\title{
How can civil society support reconciliations and civil engagement in Somalia?
}

\author{
Farhia A. Abdi' ${ }^{1}$ Kon K Madut ${ }^{* 2}$ \\ ${ }^{1}$ Taos Institute, USA \\ ${ }^{2}$ University of Ottawa, Canada
}

This article explores the role of Civil Society Organizations (CSOs) in furthering bilateral attempts by Somali regimes and the international community in restoring peace and functional social institutions in Somalia. It highlights how an inclusive reconciliation process that covers social actors and stakeholders can repair the eroded trust and fosters peaceful coexistence. The core discourse focuses on the roles played by CSOs in the negotiation and bridging gaps between communities and the government through a fair and equitable non-partisan framework for restoring peace in Somalia. The emphasis will be placed on the sociocultural dynamics CSOs can bring within the context of the process to bridge social and political gaps created by decades of civil strife. The article concluded that a quest for sustainable peace, institutional development, and effective governance requires equitable contributions and representation of the CSOs and local communities' stakeholders. Most efforts put forth by political elites in the government and the international community have faced lot of resistance because of competing interests. Therefore, it is of vital importance that political elites, community leaders, and regional bodies encourage the participation of Somali CSOs and stakeholders in all aspects of the post-conflict socio-economic and political reconstruction. The article suggests a new approach to redefine CSO roles in the reconciliation process and rehabilitation of sociopolitical and economic challenges posed by decades of the ongoing political and civil unrest in the country.

Key Words: Somalia, civil society, kinships, conflict, reconciliations, leaderships.

Article Info: Received: August 6, 2019; Revised: November 9, 2019; Accepted: November 19, 2019; Online: November 30, 2019.

\footnotetext{
${ }^{*}$ Corresponding author

Address: 75 Laurier Avenue East, Ottawa ON K1N 6N5, Canada

Phone: +613-562-5700 | Email: Kmadut@uottawa.ca
}

(C2019 Human Geographies; The authors

\section{(c) $\stackrel{G}{r}$ This work is licensed under a}

Creative Commons Attribution 4.0 International License. DOI:10.5719/hgeo.2019.132.2 


\section{Introduction}

The geopolitics of Somalia is based on ethnopolitics and traditional communal participation; therefore, contributions of civil society in the local institutional capacity-building is critical to ensure long-term sustainable peace and security in the country. Civil society in this sphere is proven to conciliate the interests of different groups over the long-term process of peace and reconciliation (Cohen \& Arato, 1994). The legacy of civil conflict is the primary cause of polarised social relationships; its recovery depends on the effort put into the education and healing process. This is where civil society can be used to promote and organise social ties that will contribute to the elements of stabilisation in a divided society (Heriots, 2002).

The fall of the last centralised government system of Somalia in 1991 has led to a prolonged and sustained political crisis that resulted in relentless human rights violations and abuses. The successive regimes have further morphed the country into chaos, displacement, and the total collapse of public institutions. Millions of Somalis were displaced from their homes and are now living abroad, with more than 1.3 million others becoming internally displaced refugees (IDR, 2003; UNDP, 2003). The term IDR is a new concept in the Somali context and, to some, it is inconceivable to describe a person who lives within their country as a displaced person or a refugee (UNDP, 2003). Somalis' livelihoods and social interactions were based on a culture of inter-reliance. Before the collapse of the central government in Somalia, its people were not exposed to forced displacements, poverty, and vulnerability within their own country (UNHCR, 2017). The country faces a humanitarian crisis because of the ongoing conflicts, including natural disasters like drought and famine.

There is a generation of Somalis who have not seen an actual functioning government, yet this generation is currently involved in the country's political and social development (UNHCR, 2017). The current government is still being protected by foreign armies (AMISOM) comprised of African countries to keep the country's executive branch and public institutions functioning. There are not enough Somali army personnel that can take over the security of the country, as they are not adequately trained or equipped (Brons, 2001). In general, these conflicts have left Somali society eroded, making post-conflict recovery and rehabilitation efforts harder. This same quagmire has been witnessed in South Sudan, Uganda, Liberia, Sierra Leone, and so many other countries that continue to recover from brutal past civil conflict (Madut, 2017). According to Lederach (1997), ethnic and tribal civil wars have different dynamics than conventional wars as they take place within communities and weaken social institutions, relations, and trust, in addition to the conventional loss of lives and resources. Lederach (1997) further asserted that "part of the challenge posed by many armed conflicts is the long-term nature of the conflicting groups' animosity, perception of enmity, and deep-rooted fear. This is coupled with the immediacy of having the enemy living virtually next door." (p. 15) 
The characteristics that eroded the social fabric of Somali communities included psychosocial wellbeing, lack of access to economic opportunities, militarism, and no inclusive political platform. Indeed, the fabric of social cohesion remains damaged, perhaps irreparably, and neighbours as well as families are still divided by the scars of the conflict in the country and diasporas. The country has not had strong and capable leadership to address and settle past grievances and thus is unable to lead the effort of reconciliations, rehabilitations, and reconstruction in the country. Those who attempted to effect change since the collapse of central government in the country have proven that corruption and abuse of power plaguing the country's military regime were indeed inevitable (Kaunain, 2017). As a result, the country needs to create a conducive environment to facilitate recovery.

Many power-sharing conferences were attempted from 1991-2004, and there has been no tangible outcome. In fact, the rush to fix and restore central power has done more harm than good due to political competition over leadership and representation, rather than compromise and reconciliation (Menkhaus, 2003). As a result, several opportunities to reevaluate the reconciliation process within Somali society were missed as the country is still trapped in a conflict cycle as pointed out by Samatar \& Samatar (2008), who further added that "It is now common knowledge that even the most promising opportunities for reconciliation and re-composition (e.g. Arta) floundered largely as a result of hapless leadership." (p. 14). It is also a well-documented fact that conflicts prompt dehumanisation of groups or collectives within the society through violations of human rights, discrimination, violence, and social deviance, which leads to distrust between communities (Allan, 2000).

\section{Social boundaries and livelihood}

There are more identifiers that unite Somali people than their strong ethnocultural affiliations with their clan, which has become a major barrier in reclaiming a collective national identity, especially after the collapse of the central government system in 1991 (Gonnelli, 2013). Like many African countries, clan identities are culturally constructed through claims of common ancestors, family, kinships, and regions with a shared language and cultural heritage (Hutchinson \& Smith, 1996; Mamdani \& Mahmood, 2018). These sociocultural factors are later adopted as a political ideology that determines the groups' social interaction, political affiliations, and access to economic opportunity as well as power-sharing and control over national resources. Indeed, the influence of clans in the political space and public institutions was inherited from the engineered colonial divideand-rule strategies adopted all over the African content (Gonnelli, 2013).

In its core, the ongoing cultural and territorial clan feuds amongst the Somalis was fueled by the colonial introduction of arbitrary international borders which ignored locals' perceptions of land, resources, and territory, thereby setting the stage for internal conflicts between clans and sub-clans (Musau, 2013). These were further complicated by the introduction of the western nation-state which gave 
larger clans the right to claim local power and the resources to ensure their loyalty (Figure 1). These policies were later adopted by national political elite who have made it difficult to socially and politically mobilise and used members of clans as a resource for political power that can challenge the status quo of the outdated politics of clan identity (Musau, 2013) who sensed that "Even with these divisions, the Somali culture is still passed down orally, and in detail, from generation to generation with clans and clannism determining one's origin, social standing and access to territory, property, and, to a large extent, power at the societal, economic and state level" (p. 13).

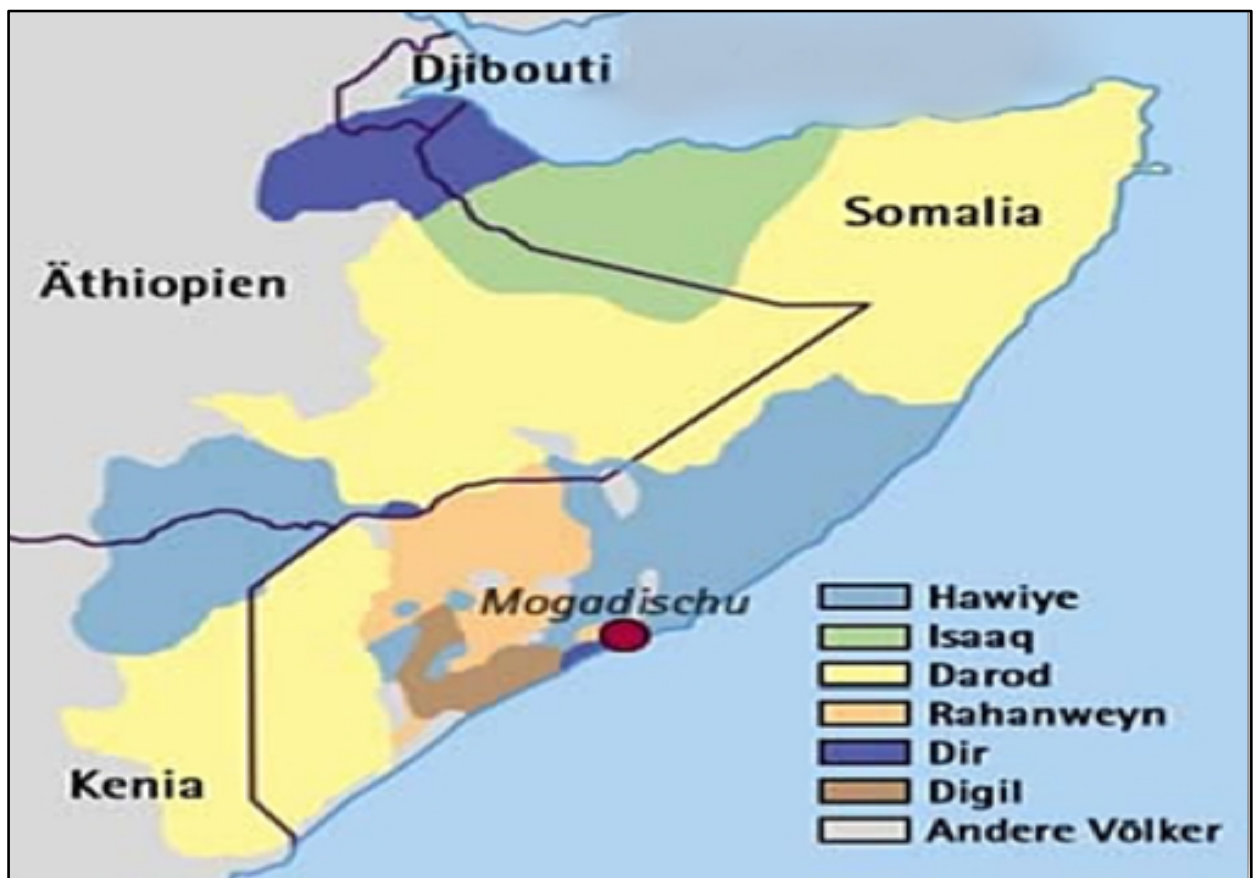

Figure 1. Somali clans

Source: The African Executive from Reconciliations to Healings

Somalis have a pastoral-nomadic and agro-pastoral society. They identify with patrilineal clan lineage; clans are divided into sub-clans, which are viewed as a source of security, solidarity, and family relations (Salwe, 1994). Clans are considered protectors of a groups' wellbeing; they manage disputes on land, water, and grazing rights. The term has recently been used as synonymous with a political party and implemented as a guardian of political power. Politically, Somalia adopted federalism in 2012 and is currently working on finalising the draft constitution based on majority/minority power-sharing and equal representation (Musau, 2013). The Somali clans' identities are derived from the descendants of two brothers: Samaale and Sab Samaale's descendants and comprise three clans: Hawiye, Darood, Dir, (including Isaq).

The Sab clan is made up of the Digil and Mirifle. The Isaaq predominate in the northwest regions, the Darod in the north-eastern, and parts of central/south 
regions, and Hawiye in central regions and Banaadir in the south. The Dir are found partially in the north and south regions (Samatar \& Laitin,1987; Abdullahi, 2001; Lewis, 1987 \& 1994). There are also minority Somali ethnic groups called Reer Hamar, who are mainly known to live in Muqdisho and Marka. This group is from a mixture of Somaal and Asian origin, and they are divided into Gibi-ad (white-skinned) and Gibil-madaw (black-skinned) (Salwe, 1994).

The minority groups consisted of the Bantus who are considered the Mushunguli, Benadiri, and Eyle. They are distinct from other Somalis in their ethnic identity, culture, and traditions, and are referred to as "Jerer," which literally means thick hair (Musau, 2013). The white-skinned are the semi Arabic Somalis including the Bajun, Barawa, and Yemen. According to Musau (2013), the Baidari group and its sub-clans occupy the north, central, and southern Somalia while the $W a$ Gosha group, also known as the forest people or the Oji, are believed to be descendants of Tanzanians, Mozambicans, and Malawians who were taken to Somalia in the $19^{\text {th }}$ century during the Arab slave trade (Gonnelli, 2013). In the context of gender, it is worth mentioning that Somalis are a culturally patriarchal society and women are not active participants in the political and social decisionmaking process. However, in 2012, during the draft of the Somali constitutional framework, Somali women were allocated $30 \%$ of parliamentarian seats but only received 14\%, an increase however from $24 \%$ in 2016 election (UNHCR, 2017).

Religion is also a significant influence in Somali lives. The population is considered 99\% Muslim, and religion has gained a strong hold in the country since the collapse of the central government. Religious elements of the clergy took a political standpoint and fought for control over the country, mainly by force. They declared war on any Somali governments that came to power. Initially, they claimed governments were controlled by foreign countries and are therefore illegitimate based on their religious values.

The first elements of the religious wing that fought with the sitting government were the Islamic Courts Union (ICU) in 2006, and they were defeated (Abdi, 2016). The Islamic Courts Union (ICU) are a network of Islamist militant tribes that controlled southern and central Somalia and fought against what they considered an Ethiopian invasion (Abdi, 2016). However, factions within ICU named Alshabaab took over the fight where the ICU left off and continue their anti-government crusade. Al-Shabaab formed in 2004 as part of the Islamic Courts Union (ICU). Alshabaab militia was added to the world's terrorist list, including Somalia's. They are known for their affiliation and ideological ties with Al-Qaeda terrorists (UNDP, 2003). These include Ahlu Sunnah Wal Jama'a, an organised Islamist group that is considered moderate by some. They are currently sharing power with the Gal-Mudug regional government (UNDP, 2003).

\section{Reconciliation framework}

Reconciliation has become a highly contested topic of the post-conflict societies and has received ample debate and discussion among scholars on international stages. The process can be overwhelming as the emotions of war carry scars that 
heal slowly; as a result, engaging in reconciliation soon after a civil war can be rejected or viewed as ineffective by the still in-conflict parties (Brandon, 2003). In the case of Somalia, the ongoing political crisis and civil unrest have not yielded an opportunity to engage in reconciliation and dialogue as part of a national agenda for recovery from the effects of the conflicts. This requires shifting the communities' attention from resolving issues of national interest by force to the adoption of reconciliation and dialogue as an effective tool of conflict resolutions and prevention of future conflict.

According to Brandon (2003), the objective of "reconciliation in the aftermath of the cessation of hostilities is no longer 'relative peace' ... but social transformation that will eventually restore broken social bonds and reinstatement of collapsed institutions" (p. 155). Similarly, Huyse (2005) thinks that reconciliation prevents the use of the past as the seed of new conflicts as it consolidates peace. The Institute for Democracy and Electoral Assistance (IDEA, 2003) also states that "reconciliation is an overarching process that includes the key instruments of justice, truth, healing, and reparation for moving from a divided past to a shared future" (p. 4).

The objectives of any reconciliation are to build sustainable peace and prevent the relapse of conflict (Loizides et al., 2010). With this premise, Somali society, like many other societies, will find itself going through a typical cycle of "societal process that involves mutual acknowledgement of past suffering, accept it as partial part of history and transform these experiences into constructive intercommunal relationships and sustainable peace" (Brouneus, 2003, p. 20). It is not the scars of war that dictate the future of a society, but the healing method that is used to resolve the cost of war and the process it requires to emerge together as one nation.

Nonetheless, for reconciliation to work, it must be tailored to the specific features of a country as every conflict has different dynamics and context (Loizides et al., 2010). Some scholars argue that anger and hatred caused by unresolved wars and human rights abuses become a self-perpetuating process. Fein (1999) demonstrates this phenomenon with the tragedies of the genocide in Rwanda and former Yugoslavia, both of which, according to her, were preceded by strong polarization between groups as well as by cycles of "crime-revenge-crime". Somalis have suffered these war consequences for more than two decades during and in the aftermath of the civil war, yet political elites appeared unprepared to address or speak of reconciliation.

This article will review the concept of reconciliation and its necessity in the Somali context, and will also look at the role civil society should play in reconciliation's effort to bridge the gap created by civil strife.

\section{The role of civil society organizations}

The role of civil society organisations (CSOs) in addressing issues of injustices and social contracts is widely accepted internationally and regarded as critical for 
holding governments accountable to their citizens, strengthening public policy, and increasing the effectiveness of development projects. Even so, the role of civil society and their effectiveness in ethnic, religious, or inter-communal conflicts is not thoroughly examined or appreciated. However, Paffenholz \& Spurk (2006) sensed that there has been little systematic analysis of the specific role of civic engagement and civil society in the context of armed conflict and even less regarding its "potential, limitations, and critical factors" (p. 1).

At its core, the concept of civil society originates from western philosophers like John Locke (1632-1704), Charles Montesquieu (1689-1755), Alexander de Tocqueville (1805-1859), Antonio Gramsci (1891-1937), and Jürgen Habermas (Paffenholz \& Spurk, 2006). These philosophers broadly discussed the role of civil society as a separate entity from the state and as an advocate agency for social justice, equality, democratisation, and humanitarian spheres. In African and other developing countries, civil society operates in a different capacity based on cultural identity and the political will that provides conducive political space for civic engagements. The role of civil society is often considered valuable and has been instrumental in influencing positive social, economic, and political change in society globally. Active civil society participation can be one apparent aim of a democratisation effort to influence the decision-making process in the state and encourage open debates on public policy (Schmidt, 2000; BMZ, 2005; USAID, 2005; Paffenholz \& Spurk, 2006).

One of the essential roles of civil society is grassroots public engagements and community developments, thereby building communities from the bottom-up and engaging them in social, economic, and political activities. This strengthens bonds among citizens and fosters harmony and peaceful coexistence among ethnic and social groups in the country (EU, 2012). The role of civil society also serves to bridge social barriers, which adds to social cohesion. In an ethnicpolitically divided society, civil society promotes dialogue and reconciliation between polarised groups (Heriots, 2002). In terms of reconciliation of civil unrest and political crisis, civil society will be the appropriate mechanism to utilise an effective intervention and reconstruction of social capital.

The civil society movement has also proven effective in addressing issues of socio-cultural rifts by educating the grassroots population and raising awareness about the importance of social acceptance and inclusion, utilising relational collaboration ideals in community initiatives and the process of healing (EU, 2012). These include modelling the roles of an agent for positive change to sustain social cohesion. For these reasons, Paffenholz and Spurk (2006) reaffirmed that civil society's role is to "promote relevant social and political themes on the public agenda" (p. 68). Therefore, the authors are suggesting the important roles and functions of the civil society be granted in the form of participation in agendasetting, lobbying for civil society's involvement in peace negotiations, creating public awareness, and international advocacy to highlight the implications of conflict on human wellbeing in Somalia.

Though the role of civil society in reconciliation can vary, its contribution cannot be overlooked. In this context, the civil society activities are interlinked 
with the community's, as they are part of their communities and know the terrain of the locals. The civil society understands the psychosocial and cultural constructions of the people and the environment since its members are part of the community, for the most part (Harvey, 1998). In Somalia, civil society can provide significant support for long-term sociopolitical sustainability to increase community capacity and receptiveness to rule of law, institutional development, and ethnic coexistence. Their contribution to all aspects of social, political, and economic engagements promotes community participation in all aspects of the nation-building process (Harvey, 1998). Reconciliation requires sustained public education and dialogue, including public engagement from all sectors and stakeholders in the society to understand the history of community relationships, unresolved grievances, and the root causes of the conflict (Crocker, 1995).

Moreover, civil society can adequately promote positive change and unity if offered support and social and political space to perform. As in the case of many African political elites, there are those who perceive reconciliation as a threat to their circle of power and authority (Paffenholz, 2009). Others procrastinate due to the fear of opening unresolved conflicts and their causes. As a result, they minimise the need for reconciliation based on the notion that past wounds will hinder their perceived notion of progress towards the future. This is a phenomenon that Bloomfield et al. (2003) referred to as a 'counterproductive' stand. They believe that "such reflection on the past is as necessary as it is painful because a divided society can only build its shared future out of its divided past. Indeed, the motivation for building a future is precisely to ensure that the past does not return" (p. 15). In this context, civil society will play an effective role in expressing and discussing important issues of social contracts as they do not perceive themselves as politician but social advocates. Most importantly, they are also a part of the grassroots community members with social capital and cultural knowledge to affect change.

The COSs will support healing and recovery efforts by focusing on a relational stance and dialogue. Without building relations, trust, and transparency in a conflict-riddled society like Somalia, an opportunity for self-healing and the ability to move forward will be lost. The kinds of actors who take part in the reconciliation process are also important, as it sets the stage for communities' trust in the process and the credibility of the facilitators involved (Miguel, 2004). This makes civil society a crucial part of any reconciliation if it is going to be successful; however, that does not mean civil societies are without controversy. As a result, the selection of members should be scrutinised and equitably reflective of ethnic, tribal, and clan sympathies within Somalia. It is equally important to recognise that reconciliation is not an easy process and, to some, it may be considered a hindrance (Hale, 2004).

As the country moves towards social healing, the reconciliation process should be approached holistically and should be a process that occurs sequentially within the broader social and political context of the conflict cycle (Murithi, 2016). It equally requires civil participation with a full partnership in the reconciliation process, its design, and decision-making process. However, the implementation 
can face challenges in planning and initiating an effective reconciliation process due to the country's limited capacity, that is, lack of political will. The presence of conflict actors in political positions also creates a fear of retribution, as well as the perception that the process may be externally driven (Murithi, 2016). Reconciliation must be nationally driven without interference of the international community in order to be effective to and reflective of the local needs. The international community should only play a supportive role by creating a conducive environment, provide technical resources, and share best practices from other countries (Murithi, 2016).

These will set a path for reconciliation and healing in Somalia for the benefit of its people and the region. As Arman (2015) explains, reconciliation is the foundation that is yet to be built for sustainable peace to materialise. According to Arman (2015) unlike the conventional wisdom of Somalia's political elite and power brokers, reconciliation is not the express gratitude, meaningless communiques, and photo opportunities. Rather, reconciliation is a deliberate and systematic process driven by a comprehensive strategic plan implemented by Somalis. Moreover, it must be implemented by Somalis who are not blinded by lan-based political fights, nor by the musical chairs game of being appointed to symbolic governmental posts (Arman, 2015). Finally, reconciliation is a critical post-conflict element necessary for healing and trust-building; it is a noble objective and a process that takes time. Its pace and broader impact could be rushed for political expedience (Paffenholz, 2009).

Therefore, developing an inclusive reconciliation framework will assist Somalia's political leaders, educators, religious institutions, and civil society in functioning in a way that is consistent with the tradition and the social consciousness of the society. The challenges that CSOs now face mainly revolve around three themes of (1) differing interpretations of civil society roles and receptibilities, (2) the absence of a unified civil society voice, and (3) internal governance challenges (Anderson \& McKnight, 2015).

Abdi (2014) stressed that Somalia still faces challenges of reconciliation, healing in the ongoing quest for peace, and sustainable functional social and public institutions. The foreseeable challenges and obstacles for creating a stable and united Somalia depend on how well the government (present and future) is willing to convince the regional governments that national unity is in the best interest of all Somalis. The inter-clan animosity and mistrust mostly emanated from the country's 1991 civil war in Somalia make this realisation difficult. However, Somali government must find ways to initiate the process of creating a conducive environment to start a process of healing and reconciliation (Abdi, 2014). In order to do that, there will be a need for an absolute peaceful political and community reconciliation and mutually agreed upon local solutions to local grievances. In this context, reconciliation should be a priority of the government's planning to achieve a coherent national unity based on respect and working with regional differences as well as negotiating, creating, and upholding common state goals and affinity (ADAN, 2015). 
Somalia's unresolved governance and conflict issues were inherited from both pre-and post-colonial rules, dogged by questions about its identity as a nation. The country is also shadowed by neighbours posing an everlasting threat and national leaders who constantly confuse personal with political issues (Ismail, 2010). It is important that the political elite, community leaders, youth, and women recommit themselves to reconciliation efforts, as well as supporting the participation of the civil society as a collective voice that will peacefully impact change and meaningful political transformation in the country.

However, this will require commitment to reconciliation, the election of competent Somali leaders with a political will to impact change, and the establishment of functional political and public institutions (ADAN, 2015). Most importantly, the reconciliation process should be locally driven, inclusive, and accommodating to Somalis from all walks of life, i.e. youth, women, and community elders, represented by effective civil society (Menkhaus, 2007). Somali people need to own the process of reconciliation and healing. They need to also learn how to discuss and reflect on the topic of reconciliation in "everyday lives, within families, and in their communities, governments, places of worship, schools, and workplaces, and to do it constructively" (Truth and Reconciliation Commission of Canada, 2015, p. 20). An active civil society plays a vital role in the reconciliation process through ongoing education, access to communities, and trust and reciprocal relationships, which will keep the carnage and the division of the past idle. An effective process of reconciliation and healing can only materialise when there is a political will within trusted political leaders who are willing to invest limited national resources in reconstruction and rehabilitation of social institutions (Menkhaus, 2007).

It has now become evident that all efforts put forth by the government or the international community were unsuccessful in Somali's reconciliation because CSOs had no role. The involvement of CSOs is one of the principal factors in determining whether post-conflict initiatives will be successful and sustainable. Bloomfield et al. (2003, p. 15) explain that "meaningful reconciliation must be grasped because ignoring it sows the seeds of later, greater failure. Furthermore, an effective reconciliation of the divided elements of a society will permit the development of cooperative patterns of working relations and envisioning the future, which will be among the strongest guarantors of successful democratization." Participation of Somali CSOs in the key decision-making process in reconciliation is vital to ensuring the sustainability and inclusivity of the process. In short, the federal government in Somalia and the international community need to engage Somali CSOs in any reconciliation process, policy development, and consultation on the decision-making process.

\section{Conclusion}

Somalia is still struggling to form a non-partisan CSO that has total legitimacy and acceptance among different communities. This has made it difficult for the 
international community and regional partners to devise a mechanism that will help civil society address complicated challenges of ethnicity, clan, and power struggles. Therefore, there is a need to rethink the intervention of civil society and expand their roles as non-partisan with a legitimate grassroots communities' support. This requires the creation of skilled CSO groups with a specific conflict and reconciliation mandate and a willingness to support local communities, government administrations, and international community partners.

The success of the CSOs in this context depends on government and international community partners to engage indigenous CSOs at local and the state levels. This will include devising a process of acquiring an equal legitimacy, development of an accountability framework, and a clear process of managing partnerships with government institutions and local and national levels. Further, the new proposed approach will also require that CSOs maintain a grassroots bottom-up approach model in working with local communities, as well as managing partnerships with other NGOs and CSOs operating in the regions to maximize their impact. Indeed, Somali civil society has an important role to play in promoting inclusion, trust, dialogue, and reconciliation, all of which are essential to building bridges in a divided society with a long history of sociopolitical and economic grievances. However, changing the approach of CSOs and their relationships will earn them necessary supports needed from the grassroots and development partners. In practice, the CSOs require to adopt an equitable participation of women and minority groups regardless of the clans, regions or tribal affiliation.

Most importantly, the local, state and federal governments cannot undermine civil society because of mistrust and exploiting ethnic divisions. Instead, the government and international community partners should create a conducive environment for CSOs to facilitate dialogue and encourage interactions between the government and the people. This includes promotions of citizens' rights and responsibilities, in order for them to become effective members in the society.

\section{References}

Anderson, D.M. and McKnight, J. (2015), "Understanding al-Shabaab: Clan, Islam, and insurgency in Kenya", Journal of Eastern African Studies, vol. 9, no. 3, p. 536-557.

Adan, A.M. (2015), Clan politics in Somalia: Consequence of culture or colonial legacy, viewed 6 August 2019, https://cutt.ly/SeIzKFh.

Abdi, F. (2014), Reconciliation and human security: Prospects of Somalia unity, viewed 15 December 2018, https://cutt.ly/BeIzZBG.

Abdi, F. (2016), Somalia: The changing discourse and the need for reconciliation, viewed 14 December 2018, https://cutt.ly/reIzCoP.

Abdullahi, M.D. (2001). The culture, custom of Somalia. Westport, Conn: Greenwood Press. 
Arman, A. (2005), Somalia, no political legitimacy without genuine reconciliation, viewed 14 December 2018, https://cutt.ly/7eIzBoz.

Allan, A. (2000), "Truth and reconciliation: A psych legal perspective", Ethnicity and Health, vol. 5, p. 191-204.

Brons, M. (2001), Society, security, sovereignty and the state in Somalia, Utrecht, International Books.

Brandon, H. (2003), "Does the truth heal? A psychological perspective on political strategies for dealing with the legacy of political violence", in N. Biggar (ed.), Burying the Past. Making Peace and Doing Justice after Civil Conflict, Washington D.C., Georgetown University Press, p.152-167.

Bloomfield, D., Barnes, T. and Huyse, L. (2003), Reconciliation after violent conflict, Stockholm, International Institute for Democracy and Electoral Assistance.

Brounéus, K. (2003), Reconciliation - Theory and practice for development cooperation, Swedish International Development Cooperation Agency.

Crocker, C.A. (1995), "The Lessons of Somalia-Not Everything Went Wrong", Foreign Affairs, vol. 74, no. 2.

Cohen, J. and Arato, A. (1994). Civil society and political theory, Boston, Massachusetts Institute of Technology.

EU (2012), Strengthening civil society in Somalia, viewed 13 December 2018, https://cutt.ly/2eIxeS1.

Fein, H. (1999), "Testing theories brutally: Armenia (1915), Bosnia (1992) and Rwanda (1994)" in L. Chorbajian and G. Shirinian (eds) Studies in comparative genocide, London, Macmillan, p. 157-64.

Gonnelli, M. (2013), Clan and state politics - Intro, viewed 17 December 2018, https://cutt.ly/QeIxyH0.

Gleditsch, N., Wallensteen, P., Eriksson, M., Sollenberg, M. and Strand, H. (2002), "Armed conflict 1946-2001: A new dataset", Journal of Peace Research, vol. 39 , no. 5, p. 615-37.

Hale, H. (2004), "Divided we stand: Institutional sources of ethno-federal state survival and collapse", World Politics, vol. 56, p. 165-93.

Huyse, L. (2005), "Reconciliation: Theory and practice" in G. Kelly and B. Hamber (eds), Reconciliation: Rhetoric or Relevant?, Belfast, Democratic Dialogue, p.7-13.

Hororwitz, D.L. (2002), "Constitutional design: Proposals versus processes" in A. Reynolds (ed), The architecture of democracy: Constitutional design, conflict management, and democracy, New York, Oxford University Press, p.45 -50.

Harvey, P. (1998), "Rehabilitation in complex political emergencies: Is rebuilding civil society the answer?", Disasters, vol. 22, no. 3, p. 200-217.

Hutchinson, J. and Smith A.D. (1996), Ethnicity, New York, Oxford University Press.

Ismail, A.A. (2010), Somali state failure players, incentives, and institutions, viewed 17 December 2018, https://cutt.ly/7eIxkuz.

Issa, S. (1994), The collapse of the Somali state: The impact of the colonial legacy, London, HAAN Publishing. 
IDEA (2003), Reconciliation after violent conflict, viewed 17 December 2018, https://cutt.ly/peIxxGe.

Kaunain R. (2017), Somalia: Overview of corruption and anti-corruption, viewed 14 December 2018, https://cutt.ly/ieIxbgb.

Laitin, D. and Samatar, S. (1987), Somalia: Nation in search of a state, London, Westview Press Inc.

Lederach, J.P. (1997), Building peace: Sustainable reconciliation in divided societies, Washington D.C., United States Institute of Peace.

Lewis, M.I. (1987), A modern history of Somalis: Nation and state in the Horn of Africa, London, Westview Press.

Lewis. M.I. (1994), Blood and bone: The call of kinship in Somali Society, Lawrenceville, NJ, The Red Sea Press.

Loizides, N., Kovras, I. and Ireton, K. (2010), "Introduction: Federalism, reconciliation, and power-sharing in post-conflict societies", Federal Governance, vol. 8, no. 2, p. 1-14.

Paffenholz, T. (2009), Civil society and peacebuilding (No. BOOK), Geneva, The Graduate Institute of International and Development Studies.

Paffenholz, T. and Spurk, C. (2006), Civil society, civic engagement, and peacebuilding. Conflict Prevention E Reconstruction, Paper No. 36, viewed 20 December 2018, https://cutt.ly/SeIxYW1.

Madut, K. (2017), "Spatiality of ethnic identity and construction of sociopolitical interaction in South Sudan", Human Geographies - Journal of Studies and Research in Human Geography, vol. 11, no. 2, p. 181-195.

Mamdani, M. (2018), Citizen and subject: Contemporary Africa and the legacy of late colonialism, Princeton, Princeton University Press.

Murithi, T. (2016), People-to-people regional reconciliation in the Horn of Africa, viewed 12 December, https://cutt.ly/6eIxIVF.

Musau, S. (2013), Clans' and clannism's control over weak political institutions, viewed 17 December 2018, https://cutt.ly/eeIxO5O.

Menkhaus, K. (2007), "Governance without government in Somalia: Spoilers, state building, and the politics of coping", International Security, vol. 31, no. 3, p. 74-106.

Miguel, E. (2004), "Tribe or nation? Nation building and public goods in Kenya versus Tanzania", World Politics, vol. 56, p. 327-62.

Menkhaus, K. (2003), "State collapse in Somalia: Second thoughts", Review of African Political Economy, vol. 97, p. 405-422.

Samatar, A. and Samatar, I. (2008), "Somali reconciliation: Editorial note", Bildhaan: An International Journal of Somali Studies, vol. 3, no. 4.

The Truth and Reconciliation Commission of Canada (2015), Honouring the Truth, reconciling for the future, viewed 20 December 2018, https://cutt.ly/JeIxXRB.

UNHCR (2017), Somali situation, viewed 14 December 2018, https://cutt.ly/weIxV9D.

USAID (2005), Increased development of a politically active civil society, viewed 14 December 2018, https://cutt.ly/6eIxMaz. 